\title{
Role of Computed Tomography (CT) in traumatic head injury evaluation - a cross-sectional study
}

\author{
Ramanana Rao D. ${ }^{1}$, Vinay NVP. ${ }^{2 *}$, Suneetha $\mathrm{K}^{\mathbf{3}}$, Chandra T. ${ }^{4}$ \\ DOI: https://doi.org/10.17511/10.17511/ijmrr.2020.i01.06
}

\footnotetext{
${ }^{1}$ D Venkata Ramanana Rao, Associate Professor, Department of Radiodiagnosis, GSL Medical College, Rajahmundry, Andhra Pradesh, India.

2* Vinay NVP, Associate Professor, Department of Radiodiagnosis, GSL Medical College, Rajahmundry, Andhra Pradesh, India.

${ }^{3}$ K S Suneetha, Resident, Department of Radiodiagnosis, GSL Medical College, Rajahmundry, Andhra Pradesh, India.

${ }^{4}$ T. Jaya Chandra, Scientist Incharge, Central Research laboratory, GSL Medical College, Rajahmundry, Andhra Pradesh, India.
}

Introduction: $\mathrm{CT}$ is the single primary modality in the evaluation of patients with acute head injuries. With these, a study was taken to find various clinico radiological patterns of head injuries and to correlate the CT features with clinical operative findings. Materials and Methods: This was a cross-sectional study carried in patients of head injury. The patients with a head injury, craniofacial trauma who underwent CT scanning were included in the study. Patients on the ventilator and with Glasgow coma scale $<6$ were excluded. Patients were scanned using dual Slice CT, Siemens somatom Emotion duo. A P-value of less than 0.05 was considered statistically significant. Results: Total 223 patients were included, $76.2 \%$ were males and $73.5 \%$ were abnormal scans. Among all intracranial traumatic lesions (ITL) the incidence of multiple ITLs were the most common (35\%) and the death rate was $12.6 \%$. Temporal bone fractures $(15.2 \%)$ were the highest. Conclusion: It was concluded that 21 - 40 years is the typical age group for head injuries, common among male and the incidence of mortality rate is more > 61 years. MICTLs are the most frequent type of hematomas.

Keywords: Injury, Brain, Report, Patient

Corresponding Author

Vinay NVP, Associate Professor, Department of Radiodiagnosis, GSL Medical College, Rajahmundry, Andhra Pradesh, India.

Email: gslcentralresearchlab@gmail.com
How to Cite this Article

Rao DVR, Vinay NVP, Suneetha KS, Chandra TJ. Role of Computed Tomography (CT) in traumatic head injury evaluation - a cross-sectional study. Int J Med Res Rev. 2020;8(1):40-44.

Available From

https://ijmrr.medresearch.in/index.php/ijmrr/article/ view/1138
To Browse

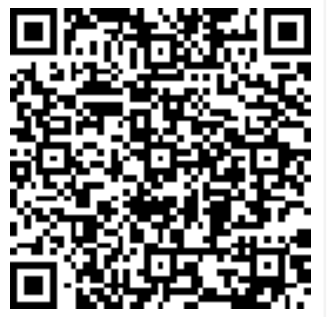

Manuscript Received 2020-01-08

Conflict of Interest No
Review Round 1 2020-01-18

Funding

Nil
Review Round 2 2020-01-24

Ethical Approval Yes
Review Round 3

Plagiarism X-checker $9 \%$
Accepted 2020-01-27

Note

(c) 2020 by D Venkata Ramanana Rao, Vinay NVP, K S Suneetha, T. Jaya Chandra and Published by Siddharth Health Research and Social Welfare Society. This is an Open Access article licensed under a Creative Commons Attribution 4.0 International icense https://creativecommons.org/licenses/by/4.0/ unported [CC BY 4.0]. 


\section{Introduction}

Traumatic brain injury (TBI) is a prevalent and potentially devastating problem. In a rapidly developing country such as India, urbanisation and industrialization is the important cause for increased road transportation this leads to head injuries due to road traffic accidents [1]. Because prompt proper management of TBI sequelae can significantly alter their course especially within $48 \mathrm{~h}$ of the injury, neuroimaging techniques, which can determine the presence and extent of the injury and guide surgical planning and minimally invasive interventions, play important roles in the acute therapy of TBI [2].

$\mathrm{CT}$ is the single most and primary modality in the evaluation of patients with acute head injuries $[3,4]$. Conventional CT is more available, cost-effective, requires shorter imaging time and easy to perform on patients on ventilator support, in traction, or agitated is the initial imaging modality of choice during the first $24 \mathrm{~h}$ after the injury [5-7]. Reduced time as well as evaluation the bone injuries are the additional advantages $[8,9]$.

Not all head trauma patients require neuroimaging. Studies have found that $<10 \%$ of patients have minor head injuries have positive findings on $\mathrm{CT}$ and less than $1 \%$ require neurosurgical intervention [10]. So, the neuroimaging is useful in low-risk patients also.

$\mathrm{CT}$ is currently the procedure of choice over MRI because it is faster and more readily available. CT is a quick, cost-effective, non-invasive method to assess the time and extent of cerebral injury. It is an essential aid to triage patients to observation, medical or surgical management. This study attempts to determine the utility of CT in the diagnosis, management and prognosis of patients with cerebral trauma.

With these, a study was taken to study the various clinical- radiological patterns of head injuries and also to correlate the $\mathrm{CT}$ features with clinical operative findings.

\section{Materials and Methods}

This is a hospital-based cross-sectional study carried out in patients of head injury referred to the GSL Medical College, Rajahmundry from October 2012 to September 2014. Informed written consent was taken from all the participants. The patients with a head injury, craniofacial trauma who under
Went CT scanning were included in the study. Patients on a ventilator and with Glasgow coma scale $<6$, who did not submit consent were excluded from the study.

Patients were scanned using Dual Slice CT, Siemens Somatom Emotion Duo. Slice thickness used $5 \mathrm{~mm}$ and available gantry tilt: \pm 20 -degree Matrix size of 512, KVP: $130 \mathrm{KV}$ and 180 MA. Proper immobilization and positioning of the head were achieved in all patients. The gantry tilt was given in the range of $\pm 0-200$, so as to parallel the scan plane to the orbito-meatal line. The obtained images were studied at brain and bone window settings. The average duration between scan and head injury was 6 to 8 hours. The patient was evaluated as per the protocol.

All patients were followed up for a period of examination to final outcome during the hospital stay after a head injury to detect any re-bleed, increased/decreased volume of hematoma and postsurgical follow up to identify residual hematoma. On the CT scans the location and extent of each lesion was identified. A search was done for the presence of blood within the ventricular system or in subarachnoid space/epidural space / subdural space. Further bone windowing was done to locate the fractures in the base of the skull or calvarium.

Statistical analysis: Statistical analysis was presented in mean, SD and percentage. Chi square test and Spearman's correlation coefficient were used for comparison of CT findings of different variables and parameters. P-value was also calculated. All statistical analyses were conducted using the SPSS statistical package.

\section{Results}

In this study, total of 223 patients with TBI were included. Gender wise, the incidence of head injuries was 170 (76.2\%) among males and 53 $(23.8 \%)$ among females (Table 1). In this, 59 (26.5\%) were found to be normal scans and 164 (73.5\%) were found to be abnormal scans.

Table-1: Gender wise study participants.

\begin{tabular}{|l|l|l|}
\hline \multicolumn{1}{|c|}{ Gender } & \multicolumn{1}{c|}{ Number } & \multicolumn{1}{c|}{ Percent } \\
\hline Female & 53 & 23.8 \\
\hline Male & 170 & 76.2 \\
\hline Total & 223 & 100.0 \\
\hline
\end{tabular}

Among all intracranial traumatic lesions (ITL) the incidence of multiple ITLs (MICTL) were the most common [78 (35\%)]. Next common ITLS were 
Contusions subarachnoid hemorrhage (CSH) [29 $(13 \%)]$ followed by epidural hematomas (EDH) [20 (9\%)], subdural hematomas (SDH) $[15(6.7 \%)]$, subarachnoid hematomas (SAH) $[11(4.9 \%)]$ and intra cerebral hematomas (ICH) $[11(4.9 \%)]$. The incidence of fractures was $123(52.5 \%)$ (Table 2$)$ and the death rate was $12.6 \%$ (28) (Table 3 ).

Table-2: Various hematomas among the study participants.

\begin{tabular}{|l|l|l|}
\hline \multicolumn{1}{|c|}{ Hematoma } & \multicolumn{1}{|c|}{ Number } & \multicolumn{1}{c|}{ Percentage } \\
\hline MICTL & 78 & 35 \\
\hline CSH & 29 & 13 \\
\hline EDH & 20 & 9 \\
\hline SDH & 15 & 6.7 \\
\hline SAH & 11 & 4.9 \\
\hline ICH & 11 & 4.9 \\
\hline
\end{tabular}

Table-3: Mortality rate among the study participants.

\begin{tabular}{|l|l|l|}
\hline \multicolumn{1}{|c|}{ Mortality } & \multicolumn{1}{c|}{ Frequency } & \multicolumn{1}{c|}{ Percent } \\
\hline No & 195 & 87.4 \\
\hline Yes & 28 & 12.6 \\
\hline Total & 223 & 100.0 \\
\hline
\end{tabular}

Coming to the type of fracture, temporal bone fractures $(15.2 \%)$ were the highest followed by multiple fractures $(9.9 \%)$, occipital bone $(6.7 \%)$ and parietal bone fractures $(4.9 \%)$ and craniofacial fractures $(4.9 \%)$, depressed fractures $(4.5 \%)$ and comminuted fractures $(1.3 \%)$. Multiple ITLs were the most common hematomas found in all age groups except in $<20$ years most common lesions are epidural hematoma followed by contusions. In 21 - 40 years age group second most common were contusions followed by epidural hematoma. In $41-$ 60 years contusions are commonly followed by subdural hematoma. In $>61$ years age group, subdural hematomas were the most common followed by contusions (Table 4).

Table-4: Age wise distribution of various hematomas.

\begin{tabular}{|l|l|l|l|l|l|}
\hline Age in years & \multicolumn{1}{|c|}{ CSH } & \multicolumn{1}{|c|}{ SDH } & \multicolumn{1}{|c|}{ EDH } & \multicolumn{1}{|c|}{ SAH } & ICH \\
\hline$<20$ year & 3 & 2 & 5 & 1 & 0 \\
\hline $21-40$ & 15 & 3 & 11 & 5 & 5 \\
\hline $41-60$ & 8 & 6 & 3 & 5 & 4 \\
\hline$>61$ & 3 & 4 & 1 & 0 & 2 \\
\hline Total & $29(13 \%)$ & $15(6.7 \%)$ & $20(9 \%)$ & $11(4.9 \%)$ & $11(4.9 \%)$ \\
\hline P value & 0.988 & 0.07 & 0.139 & 0.451 & 0.542 \\
\hline
\end{tabular}

\section{Discussion}

Head injury is a frequent cause of death and
Disability in developing countries like India. The incidence of TBI is increasing as traffic increases, besides other confounding factors such as industrialization, falls and ballistic trauma. CT facilitates a comprehensive diagnosis and targeted interventions.

An earlier study by Asaleye CM et al., [11] in patients with moderate to severe head injury showed that $87 \%$ of patients had abnormal CT findings. Whereas in this study, $73.5 \%$ individuals had abnormal findings due to head injuries.

In this study the incidence of TBIs is common among 21 - 40 years $(48.9 \%)$ age group followed by $41-60$ years age group $(28.3 \%)$ and $<20$ years age group (11.7\%). The incidence among the $>61$ years age group was $11.2 \%$. This is similar to study done by Zimmerman and Bilaniuk [12] and Satish Prasad BS, Shama M Shetty [13] reported maximum injuries in the age group of $19-50$ years $(79 \%)$, people $>50$ were $21 \%$. Whereas $\mathrm{K} \mathrm{J}$ VanDongen et al. [14] reported contrast findings compared to the present study, the investigators reported that < 20years (40\%) was maximum incidence followed by $21-40$ years and $40-60$ years. The increased incidence in this study among the age group of $21-40$ years was explained by the fact that these were the people who were active in life and who ride motorized two-wheelers and four-wheelers and are hit by the heavy vehicles in the road traffic accidents. Similar findings were reported by Seelig JM, Becker et al., [15] and Narayan RK et al [16].

In this study males had a higher rate $(76.2 \%)$ of head trauma compared to females $(23.8 \%)$, the male-female ratio was $3: 1$. Clifton GL et al., [17] in their study found the male to female ratio $5: 1$. Satish Prasad BS and Shama M Shetty [13] reported male to female ratio 9:1. The mortality rate among males is higher than females. Kraus JF, Peek ASA et al [18] found no significant difference between the outcome and gender. It was found that more males suffered from head trauma as compared to females because of the exposure of males to traffic and outdoor activities than females in India. Our findings were consistent with Bharti et al., [19] who reported that males were predominantly involved with head injuries $(85 \%)$.

This study reveals that $35 \%$ of patients had more than one finding on CT Among the various CT findings the incidence of multiple intracranial traumatic lesions was $35 \%$. Multiple hematomas are 
Most common ITLs in this study. This can be explained by more number of cases brought to the hospital were associated with heavy motor vehicle accidents not a simple accident because the hospital situated near the national highway so heavy vehicular traffic is more. Next common ITLS were contusions subarachnoid hemorrhage (CSH) [29 $(13 \%)]$ followed by epidural hematomas (EDH) [20 (9\%)], subdural hematomas (SDH) $[15(6.7 \%)]$, subarachnoid hematomas (SAH) $[11(4.9 \%)]$ and intracerebral hematomas (ICH) [11 (4.9\%)]. As compared to Ashok Nyak et al. showed contusions were the most common ITLs [20].

This study showed 15 cases of SDH. Majority of the patients were in the age group of $41-60$ years and $>61$ years. According to Seeling et al., [21] study, SDH occurred approximately $5 \%$ to $22 \%$ of patients with a severe head injury as reported by and was the most lethal of all head injuries due to its association with concomitant parenchymal brain injuries. In the present study, it was found in $19.37 \%$ of the patients.

Acute subdural haematoma (ASDH) is still a condition with high mortality and morbidity. The reported incidence of ASDH is as high as $5 \%$ in patients with head trauma and some retrospective studies report increased incidence with age [ 22]. The incidence of EDH [20 (9\%)] is higher than the $\mathrm{SDH}$ in this study, is third commonest hematoma found next to MICTL and contusions. EDH is most frequent than $\mathrm{SDH}$ because in the most age group who were prone to accidents are young people, correlated with age incidence of EDH.

The range of traumatic SAH was reported from $12 \%$ to $44 \%$ [23]. In the present study, it was $11(4.9 \%)$ cases out of 223 patients. More frequent in 21-60 years age group. By location, diffuse involvement is most common followed by frontal-parietal region. Parietal bone fractures followed by multiple fractures associated with SAH.

According to Hirsh., ICH of the frontal and temporal lobe was commonest in head injuries [24]. In the present study, the ICH was found in 11 patients $(4.5 \%)$ in the frontoparietal location followed by diffuse involvement. This is similar to Nayak Ashok et al [20] findings.

\section{Limitation}

Inclusion of craniofacial trauma alone is the limitation of the study. The small sample size is another major limitation of the study.

\section{Conclusion}

As per the study findings, it was concluded that 21 - 40 years is the common age group prone for head injuries, common among male and the incidence of mortality rate is more in the age group above 61 years. MICTL are the most frequent type of hematomas.

\section{What does the study add to the existing knowledge}

The age group ranged between 21 - 40 years is commonly prone for head injuries and CT help in evaluation.

\section{Author's Contribution}

Dr. D Pottala Krishna Mohan: Study design, data analysis, paper writing.

Dr. Vinay NVP: Study design, paper writing.

Dr. K S Suneetha: Main work, data analysis

Dr. T Jaya Chandra: Data analysis, paper writing, statistical part.

\section{Reference}

01. Osborn, Salzman, Barkovich, Katzman. Provenzale, Hansberger, diagnostic imaging brain - 2nd edition. Lippincott Williams \& Wilkins. 2009.

[Crossref]

02. Hoyt DB, Holcomb J, Abraham E, Atkins J, Sopko G. Working Group on Trauma Research Program Summary Report- National Heart Lung Blood Institute (NHLBI), National Institute of General Medical Sciences (NIGMS), and National Institute of Neurological Disorders and Stroke (NINDS) of the National Institutes of Health (NIH), and the Department of Defense (DOD). J Trauma. 2004;57(2)410-415. doi: [Article] [Crossref]

03. Andy Adam Adrian Dixon Jonathan Gillard Cornelia Schaefer-Prokop Ronald Grainger. Grainger and Allison's diagnostic radiology. 5th ed, Elsevier. 2014;pp 78.

[Crossref]

04. John Haaga Daniel Boll. CT and MRI of the whole body. 5th ed, Elsevier. 2008; pp-295.

[Crossref] 
05. Miller EC, Holmes JF, Derlet RW. Utilizing clinical factors to reduce head CT scan ordering for minor head trauma patients. J Emerg Med. $1997 ; 15(4) 453-457$.

doi: [Article] [Crossref]

06. Kelly AB, Zimmerman RD, Snow RB, Gandy SE, Heier LA, Deck MD. Head trauma- comparison of $\mathrm{MR}$ and CT-experience in 100 patients. Am J Neuroradiol. 1988;9(4)699-708.

[Crossref]

07. Glauser J. Head injury- which patients need imaging?, Which test is best?. Cleve Clin J Med. 2004;71(4)353-357. doi: [Article] [Crossref]

08. Jones TR, Kaplan RT, Lane B, Atlas SW, Rubin GD. Single versus multi detector row CT of the brain quality assessment. Radiol. $2001 ; 219(3) 750-755$.

doi: [Article] [Crossref]

09. Yealy DM, Hogan DE. Imaging after head trauma, Who needs what?. Emerg Med Clin North Am. 1991;9(4)707-717.

[Crossref]

10. Ambrose J, Honsfield G. Computed axial tomography. British J Radiol. 1973;46(542)148149.

[Crossref]

11. Asaleye CM, Famurewa OC, Komolafe EO, Komolafe MA, Amusa YB. The pattern of Computerized Topographic findings in moderate and severe head injuries in ILE- IFE, Nigeria. West Afr J Radiol. 2005;12;8-13.

[Crossref]

12. Zimmerman RA, Bilaniuk LT, Hackney DB, Goldberg HI. Head injury- Early results of comparing CT and high field MR. Amj Neuro Radiol. 1986;147(6)1215-1222. doi: [Article] [Crossref]

13. Satish Prasad BS, Shama M Shetty. Evaluation of craniocerebral Trauma Using Computed Tomography. J Dental and Med Sci. 2014;13(9)57-62. [Crossref]

14. Van Dongen KJ, Reinder, Geert J. The prognostic value of CT in comatosed head injured patients. The J Neuro Surg. 1983;59(6)951-957. doi: [Article] [Crossref]
15. Karibe H, Hayashi T, Hirano T, Kameyama $M$, Nakagawa A, Tominaga T. Surgical management of traumatic acute subdural hematoma in adults- a review. Neurol Med Chir (Tokyo). 2014;54(11)887-894.

doi: [Article] [Crossref]

16. Narayan RK, Greenberg RP, Miller JD, Enas GG, Choi SC, Kishore PR. Improved confidence of outcome prediction in severe head injury- A comparative analysis of the clinical examination, multi-modality evoked potentials, CT scanning, and intracranial pressure. J Neuro surg. $1981 ; 54(6) 751-762$. doi: [Article] [Crossref]

17. Clifton GL, Grossman RG, Makela ME, Miner ME. Neurological course and correlated computed tomography findings after severe closed head injury. J Neuro Sur. 1980;52(5)611-624. doi: [Article] [Crossref]

18. Kraus JF, Peek-Asa C, McArthur D. The independent effect of gender on outcomes following traumatic brain injury- a preliminary investigation. Neurosurg Focus. 2000;8(1)e5. doi: [Article] [Crossref]

19. Bharti $P$, Nagar AM, Tyagi U. Pattern of trauma in western Uttar Pradesh. Neurol India. $1993 ; 42 ; 49-50$.

[Crossref]

20. Nayak A, Gupta MM, Shivam P. An analytic study of traumatic intra cerebral hematomas. Neurol India. $1993 ; 41 ; 217-222$.

[Crossref]

21. Seeling JM, Becker DP. Traumatic acute subdural haematoma. N Engl J Med. 1981;304(25)15111518.

[Article] [Crossref]

22. Takizawa T, Sato S. Traumatic subarachnoid haemorrhage. Neuro Med Chir. 1984;24;390395.

[Crossref]

23. Koc RK, Akdemir H, Oktem IS, Meral M, Menku A. Acute subdural hematoma: outcome and outcome prediction. Neurosurg Rev. 1997;20(4)239-244. doi: [Article] [Crossref]

24. Hirsh LF. Delayed traumatic intracerebral haematomas. Neurosurg. 1979;5(6)653-655.

[Article] [Crossref] 